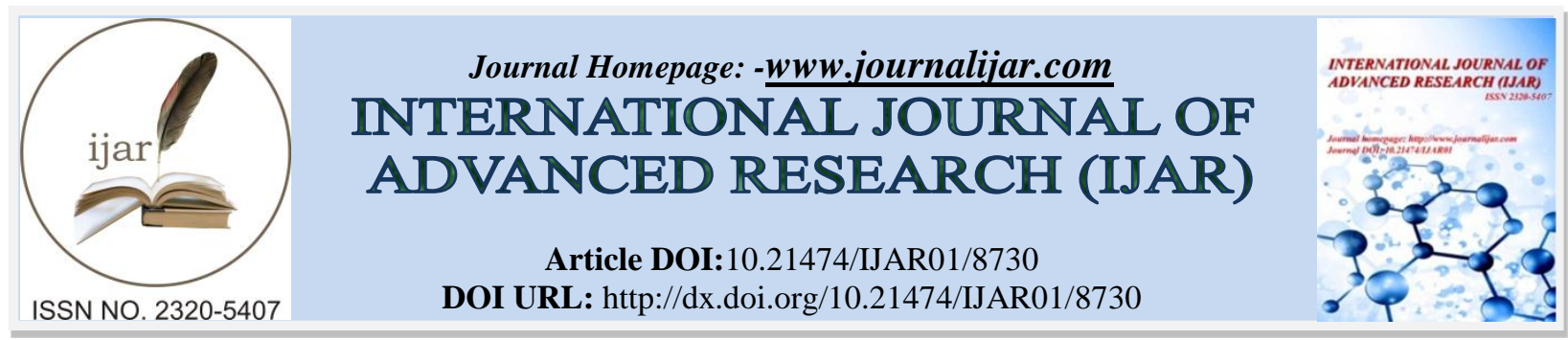

RESEARCH ARTICLE

\title{
THE CONTRIBUTION OF GEOGRAPHIC INFORMATION SYSTEMS AND REMOTE SENSING IN URBAN MANAGEMENT: CASE OF URBAN AGENCIES IN MOROCCO.
}

Youssef EL Mdari, Abdelouahed Namir and Mustapha Hakdaoui.

hassan II university of casablanca, ben m'sik faculty of sciences, LTIM laboratory.

\section{Manuscript Info}

Manuscript History

Received: 18 January 2019

Final Accepted: 20 February 2019

Published: March 2019

\begin{abstract}
Morocco has known a strong increase in urban population due to population growth, urban migration, and many other social, economic parameters. This urbanization introduces quite complex phenomena, generating a multitude of problems: transportation, lack of social facilities, environmental degradation, management of urban space, etc. The urban (1) agencies were created to control this phenomenon through the development of planning documents defining the rules for land use and monitoring of urban activities. Geographic Information Systems (GIS) and Remote Sensing are now positioned as powerful tools for decision support, particularly as regards the management of space. The integration of the spatial dimension, thanks to GIS, allows locating information and better organizing data in a more user-friendly way. Some procedures in the urban agencies are based on standard geographical documents.
\end{abstract}

Copy Right, IJAR, 2019,. All rights reserved.

\section{Introduction:-}

Throughout the twentieth century, Morocco has experienced a very strong increase in urban population due simultaneously to population growth and rural exodus. In addition to this phenomenon, there is a significant dynamics affecting the urban network itself involving a large development of urbanization. The number of municipalities ${ }^{(2)}$ increased ${ }^{(3)}$ from 29 in 1971 to 45 in 1982 and are today more than 240 . This urbanization, which introduces quite complex phenomena to the city, has generated difficulties in the management of space and a multitude of problems ensued:

1. Difficulty to control planning of cities;

2. Circulation and transport;

3. Environmental degradation;

4. Urban Management

Moroccan urban ensemble appears well classified: three cities with over one million inhabitants (Casablanca, Rabat - Salé and Fez); a dozen major cities with over 100,000 inhabitants whose regional capitals are Marrakech (870 000 inhab.), Meknes (500 000 inhab.), Tangier (500 000 inhab.), Agadir (500 000 inhab.) and Oujda (260 000 inhab.); medium-sized cities revolving around the major centers; forty small cities and many local centers.

The rapid population growth which marked the country over the past four decades has had major consequence of aggravating the imbalances between regions and uneven development within the same urban area. The contrast has 
continued to deepen between poor and rich region between equipped planned areas and under-equipped spontaneous settlements. Facing these demographic and urban issues, the administration has gradually established a series of institutional arrangements and planning instruments whose stated purpose is to control and rationalize urban space.

But centralism remains the major feature of all of these administrative arrangements, both in terms of organization and in terms of skills. The administrative network in place intends to ensure supervision of the territory and aims to enable the centralism and their territorial extensions control over decision-making and resource allocation at city level

Urban agencies handle daily large amounts of geographic data. To this end, the issue of implementation of a geographic information system is important. This study aims to draw up a report on urban management in Morocco and deepen, theoretically and practically, the implementation of GIS for urban management to automatically generate information notes within these agencies. How to restructure the existing spatial databases to launch a GIS application to renovate urban management?

\section{Cityscape in question: evolution and challenges of the Moroccan city}

Morocco urbanization growth rate has accelerated (4): 29\% in 1960 to 35\% in 1971, 43\% in 1982 and 59\% in 2012. Based on these statistics, we can say that the urban challenge is the one of the major issues of the contemporary period as well for developed countries than for developing countries. This growth implies an increase in housing needs, equipment, services, education, jobs ... and the social and spatial transformations, but more importantly, it encourages rethinking the design of the planning of our cities and the terms of urban management.

The urban agencies were created to control this phenomenon through the establishment of planning documents defining the rules of land use and control of urban activities. In recent years, some urban agencies started using information and communications technology (ICT) and new technologies of representation and space management (GIS, remote sensing,) to automate and computerize their services because of the progress of urbanization in Morocco. The growing volume of data requires the use of latest technologies, particularly spatial dimension.... Urban agencies perform the main tasks of GIS namely information, production and decision on one hand, and produce cartographic documents, on the other.

\section{The role of urban agencies in Morocco in urban management}

The 30 urban agencies accumulated expertise and territorial engineering to the point where they became centers of multidisciplinary resources and skills in the field of urban planning. The urban agencies have appeared in the Moroccan institutional landscape in the wake of the administrative reforms tried in Casablanca, following the urban riots of 1981 and 1984. Their structure is of double dimension: political and technical. This is to ensure better social control by solving the main problems related to city development.

The urban agency has broad prerogatives: playing the role of a public design office and providing support to local authorities in the thinking and planning strategies, concerning urbanism, territory development and "management". The agency is held responsible for:

Collect and circulate information about the urban development of the prefectures and / or provinces in its territorial jurisdiction.

Conduct necessary studies for the establishment of urban development master plans (SDAU) and monitor the implementation of the guidelines defined therein.

Prepare regulatory planning documents projects, including zoning plans, development plans.

Conduct development projects studies of particular sectors and execute all projects when it comes to public interest.

Provide technical assistance to local authorities in urban planning and development and to public and private operators.

In France, the planning agency, investigation and study organization, was founded at the initiative of local authorities (mainly in large cities) to serve as a support tool in the definition and harmonization of public policies for 
development and planning. The urban agency of Morocco was created by the State, generating a tense climate, especially with the communal councils acting reluctantly in respect to this institution which, in their opinion, "monopolizes the framework on production of urban space "(Chouiki, 1996) at the expense of the powers vested by their communal charter. Although this state of tension eased over the years with the generalization of urban agencies, to become an irreversible fact, the pulling of competences still exist and the friction between these, the elected ones and the territorial authorities persist, particularly because of issues related to urban management.

Considering the demands of territorial competitiveness, the concerns and priorities of the urban agency are to be reconsidered to convert it into a real vector of knowledge and spatial development. In doing so, an institutional reorganization is necessary to overcome the vicissitudes of urban governance and build or strengthen the culture of synergy between the various actors.

Urban growth is accompanied by the proliferation of information that describes the urban territory and its inhabitants: location of activities, means of transportation, equipment, green spaces, property and asset management, etc. All these information relates in one way or another to a location attribute, whether it is accessible in the form of precise registration or in form of aggregation available according to predefined divisions. Their visualization in plans or maps remains one of the simplest and most pertinent ways of apprehending them (Steinberg, 2003).

The interest of the localized information in GIS can play a key role, first as a research tool, but also in the daily work of the urban agency. Despite the lack of the use of operational GIS in urban agencies, renewed interest is seeing the day for the use of these tools.

\section{Using GIS in urban agencies in Morocco}

Nowadays, the management of a city encompasses fields of competence of a great extent. The population is constantly growing, the need for new resources and infrastructure follows. In addition, various municipal services have increasingly large powers, and paradoxically, they also see themselves more dependent of each other. Thus, policymakers need tools to ensure coordination of these actors, particularly as new environmental and sustainable development standards are added. This means new and restrictive rules that make the decision more difficult. Given this fact, GIS is proving to be powerful urban management tools.

The combination of computer and digital mapping provides decision makers with the means to make wise choices (Prélaz-Droux, 1995).

Mastering information has always been a major concern at all levels,. This issue is essential, especially with regard to land management. The explosion of new technologies and IT in all sectors suggests a more rapid development of global databases. The administration is packed with information, usually with spatial characters, certainly exploited using databases but not oriented to the spatialisation of the phenomena (Didier, 1990). As such urban management, in general, cannot escape this trend. The informations covered in this field are particularly varied and transdisciplinary and require the use of databases to try to cross several informations between them and thereby generate new information and ideas. Information systems develop accordingly very quickly with the institutions that manage daily urban and environmental phenomena. However, these spatial connotation systems are not present or at least weakly used for land management (Edge and Baduel, 2004). For agencies, good urban management goes one way or another by good control of information. GIS and remote sensing are essentials tools for the decision-makers (Souris, 1986). Moroccan urban agencies use GIS in processing their archives.

\section{GIS application Example in Moroccan urban agencies}

Geomatics aims to manage spatial data and uses science and technologies related to their acquisition, storage, processing and dissemination. Science and geomatics technologies are used for surveying, cartography, geodesy, photogrammetry, remote sensing and computing. Geomatics therefore not only provides the means for acquiring localized digital data (geodesy, photogrammetry and remote sensing), but also the management tools, analysis and representation of geographic information.

In this context, GIS represents the synthesis of the advances in digital processing of geographic information as they allow placing georeferenced data acquired by various geomatics methods in a coherent framework, analyzing and mapping them. Didier Michel (1990) defines GIS as "a set of data identified in space, and structured in a way to allow the extraction of syntheses useful for decision making." This definition lends well enough to be role 
assigned to this tool in our study. Today, GIS mark their presence in numerous professional organizations: governments or local collectivities, environmental studies offices,

The urban agencies meet the main tasks of a GIS: information, production and decision. From this perspective, GIS is a great tool that allows for an urban agency:

1. integration, management, centralization into databases and updating, if necessary, of all the data involved in the trade, such as map data, photogrammetry, remote sensing and socioeconomic;

2. archiving management plans in vector digital format for preservation and inter-derogation of these plans;

3. consultation and browsing management plans (7) (Fig. 1) and regulatory databases;

4. automating the generation of the information note;

5. consultation of the exemptions;

6. management and early consultation of offenses;

7. sharing and dissemination of geographical data with both inside and outside access to an organization that would only be possible by GIS web technology. In the case of urban agencies, coordination between the different divisions, departments and services should be ensured, it should also ensure the dissemination of information to the public.

This list is far from being exhaustive. The use of GIS is very relevant to automate much of the business processes of urban management, including mapping. The urban agencies use GIS for the integration of development plans in a database and its operations in a shared environment to automatically generate notes of intelligence.

\section{Automatic generation of information notes within urban agencies}

Once the regulatory documents, such as the development plan are established, a wide dissemination of the provisions set out therein. The information note is the administrative document issued exclusively by urban agencies that inform citizens (the owner or his representative) on the regulatory provisions of the planning documents (management plan) for one or more terrains, about the allocation reserved for the land in question by planning documents (housing, industry, trade ...) and the regulations applicable to the area where the field is located.

This document facilitates the orientation of the citizen in the consistency and project design to achieve on the land in question, and avoids all technical and administrative obstacles which usually originate by a lack of knowledge about:

1. The position of the land relative to zoning;

2. Urbanistic standards to be observed during the project;

3. The procedure for the constitution of records.

The information note is part of the urban agencies activities and is of great importance because it allows for the agency, the acceleration of instruction procedures, and for citizens anxious to know the regulations of the use of his land and contribute to urban development. This is the result of the intersection map data (graphics settlement documents ...) on one side and documentary data (settlement documents, supporting reports ...) on the other. To generate this note, it must first locate the requested parcel of land on the zoning plan from its coordinates or to identify the number of its land title, then determine the spatial intersection of the plot with different areas of the map (eg with the tourist area, the industrial area, the habitat area, green spaces, public facilities, roads ...). Finally the information note is provided to the applicant

\section{Note of information Management System in the urban agency}

Most urban agencies use AutoCAD software (8) to generate the information note. The responsible of this task locates the plot from its geographical coordinates on AutoCAD, then he visually determine the different areas that make up the plot (ie spatial intersections with different areas of the development plan) and Regulation which defines the rules for land use and construction applicable to each area. Among the constraints, we can mention: the difficulty of determining the areas that make up the parcel, the lack of connection between the alphanumeric database and geometric objects and formatting of printed documents (states provided to the applicant).

However, all these constraints in the AutoCAD management of information notes disappear with the use of GIS that integrate within the same tool techniques of mapping and database management. 


\section{Using GIS for generating information notes}

Currently, there are several software tools to develop a GIS. The geometric and alphanumeric data is stored in the same database (Database Management System: DBMS Oracle 10g), the manipulation (visualization, query, add, delete, update ...) of geometric data is managed by a cartographic platform ArcGis (9) (Fig.2).

The conceptual data model contains the following entities: "records" (containing information about the application files of the intelligence note), "seekers", "plots" (containing the references and details of the plot, the zoning plan, municipal and provincial boundaries). The interfaces of the application

(Figure 3) proposed are designed to facilitate the management of the note information. The procedure for using this application is as follows:

1. loading map (zoning plan) from the application;

2. localization of a parcel from its coordinates, its land title number, or file number if this information is already entered in the database;

3. the drawing, , of the plot on the map automatically generated by the system and the calculation of its spatial intersections through the various layers of the map;

4. The regulations of the parcel, the zoning map and other documents relating to the information note.

GIS store, analyze and display data including those of spatial references. These systems have attracted great interest in many fields, especially in the development of urban space. However, on the downside, it is recognized that the implementation of a GIS generates significant costs in the purchase of software, hardware and data acquisition expertise.

In this article we presented the GIS application that was developed for urban management, particularly the management of the information note of the urban agency. This application has improved the performance of the service responsible for managing the information note in terms of time and reliability of data provided to applicants.

\section{Conclusion:-}

Urban management and planning are important issues for a country concerned for its sustainable development, namely Morocco. The agencies in charge of these tasks still face problems related to the increased volume of data to manage, business processes that often seem slow and uncoordinated, incoherence, especially as regards the geographic data, the sharing of difficulties and simultaneous access to data, loss of time due to some manual processing, archiving and scaling, etc.

This requires the use of modern means of land management such as GIS, geographic databases that facilitate traditional work. The use of GIS should constitute a considerable gain in time. Urban management is a complex process that requires a substantial base of information and coordination between different actors (including urban agency, prefecture, and municipality) of urban space. In developing countries, this management is made more difficult by the lack of financial resources and technical skills. For this reason, the traditional tools of the development do not have the desired efficiency. Instruments such as GIS greatly increase the phenomena of urban management. The success of the GIS project will be measured by the willingness of city stakeholders to work together for a shared regional project on common themes. In addition, the exchange and sharing data will better qualify them, avoid duplication and ultimately increase efficiency by pooling efforts.

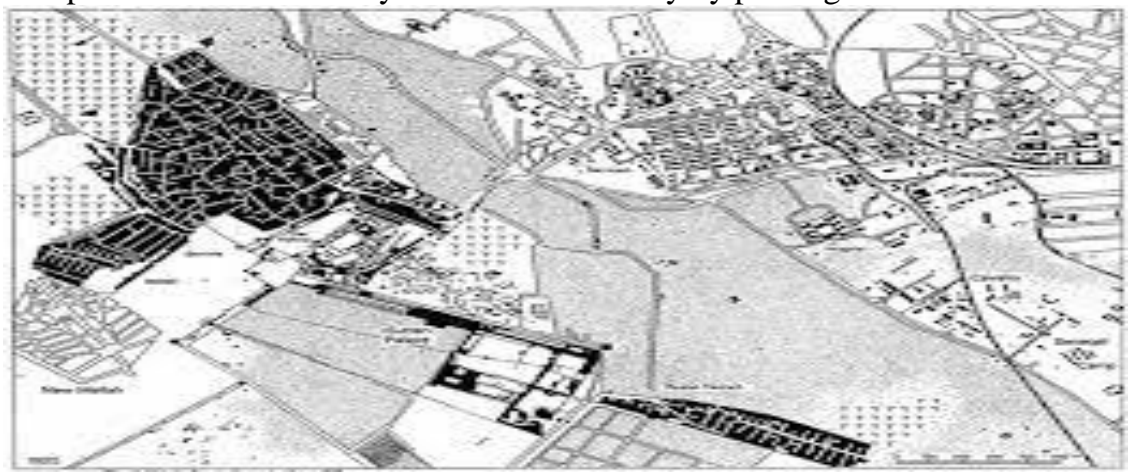

Figure 1:-Extract of a PA scanned 


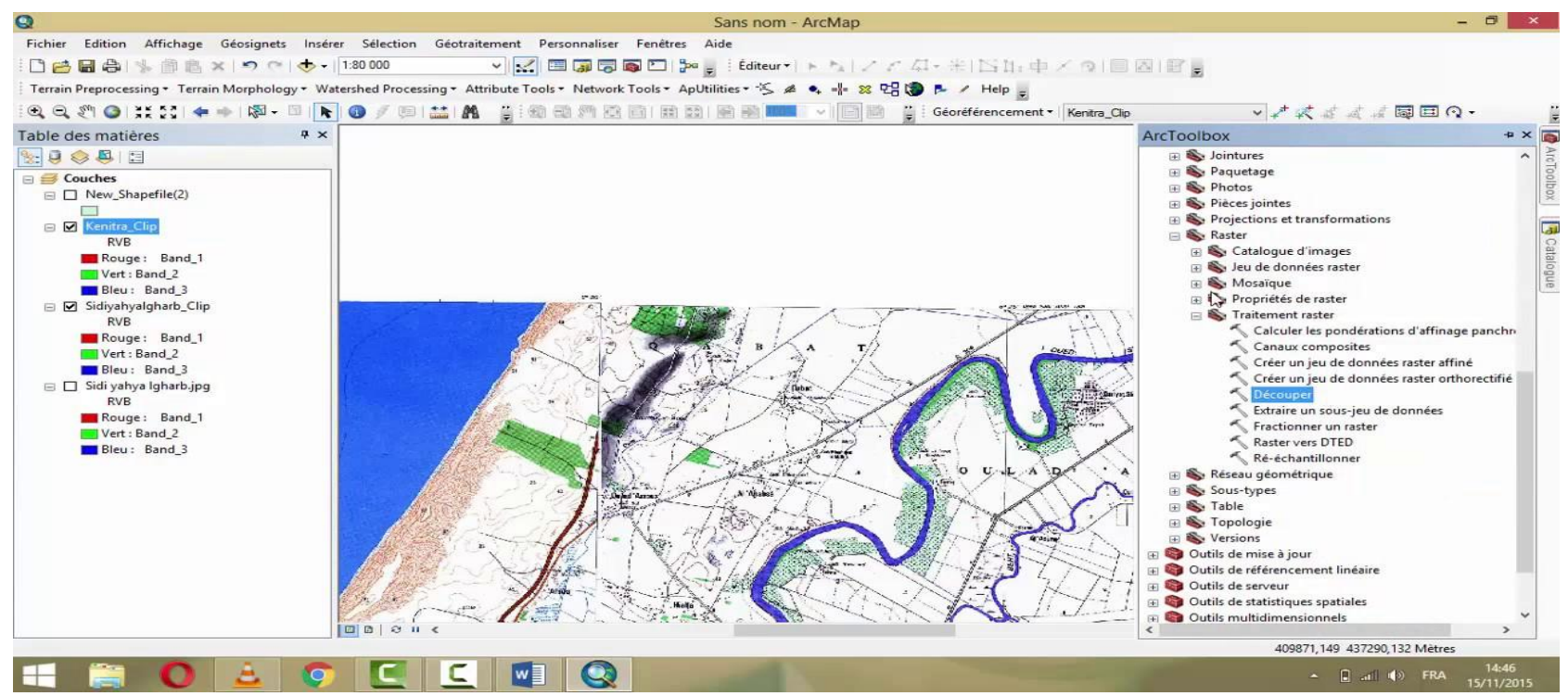

Figure 2:-Result of data editing

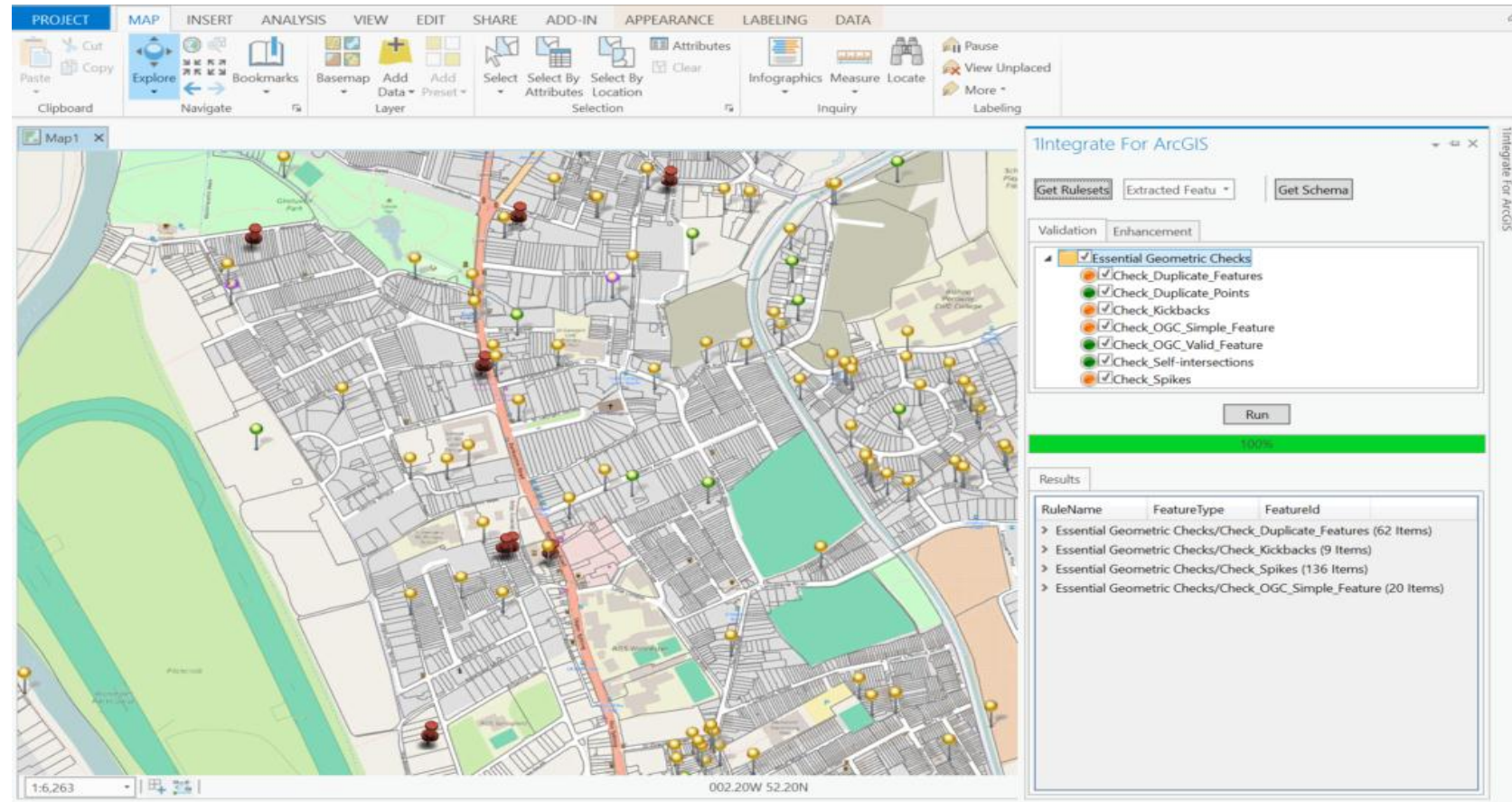

Figure 3:-Example of the management module of the information note

\section{Bibliography and References:-}

1. Urban agencies are organizations at the provincial or regional level, responsible for management and planning, ensuring territorial engineering. This involvement is essential. Each agency has an urban territories which corresponds to a number of prefectures and / or provinces to which belong the urban and rural towns

2. Municipalities are local authorities under public law, with financial autonomySource: High Commission for Planning (HCP, 2014) http://www.hcp.ma.Source: High Commission for Planning (HCP, 2014).

3. Article 3 of the Dahir No. 1.93 .51 of 10 September 1993 establishing urban agencies. Dahir denotes a royal decree in Moroccan law it means the seal of King affixed to the texts of laws voted in parliament.

4. The urban agency gives an assent on the projects of subdivisions, groups of habitants and constructions, the president of the communal council must obtain the assent of the urban agency before deciding and giving the authorization of said projects. 
5. The development plan is one of the regulatory urban planning documents. It defines the right of land use within the territories to which it applies. It is an instrument that transforms the orientations of the SDAU,

6. Autocad is Computer Aided Drafting (CAD) software created in December 1982 by Autodesk.

7. 9- ArcGIS is a set of geographic information software developed by the American company Esri (Environmental Systems Research Institute

8. Edge Jean-Paul and Pierre Robert Baduel, 2004 Cards of knowledge, Paris, Karthala Editions (ISBN 2-84586488-4), 679 p.

9. Bordin Patricia, 2002 GIS concepts, tools and data, Paris, Hermes Science Publishing (ISBN 2-7462-0554-8), $257 \mathrm{p}$.

10. Chouiki El Mostafa, 1996, Casablanca, socio-spatial approach publication of the Faculty of Humanities, Casablanca-AinChock, $250 \mathrm{p}$.

11. Denegre Salgé Jean and François, 1996, 2004, Geographic information systems. Paris, PUF, 126 p.

12. Didier Michel, 1990 Usefulness and value of geographic information, Paris, Economica, STU, CNIG. 255 p.

13. Prelaz-Droux Roland, 1995. Information System and Land Management: systemic approach and processing realization, Coll. Meta, Lausanne, polytechnic and university presses in Western Switzerland, $156 \mathrm{p}$.

14. Mouse Mark, 1986 geographical information and database systems, Conferences and Seminars Treatment of localized data, Paris, Editions ORSTOM, 1986, p. 29-87.

15. Steinberg John, 2003 Cartography: remote sensing and geographic information systems. Campus, Armand Colin. $159 \mathrm{p}$.

16. High Commission web site map: http://www.hcp.ma 